\title{
Fine needle aspiration cytology of recurrent dermatofibrosarcoma protuberans presenting as a chest wall mass
}

\author{
Jadhav M.N. ${ }^{1}$, Kempula G. ${ }^{2}$, Haravi R.M. ${ }^{3}$, Kittur S.K. ${ }^{4}$ \\ ${ }^{1}$ Dr. Meena N. Jadhav, Associate Professor, ${ }^{2}$ Dr. Geethamala Kempula, Assistant Professor, ${ }^{3}$ Dr. Rekha M. Haravi, \\ Associate Professor, ${ }^{4}$ Dr. Shreekant K. Kittur, Professor and Head, all authors are affiliated with Department of \\ Pathology, Belagavi Institute of Medical Sciences, Belagavi, Karnataka, India.
}

Address for Correspondence: Dr. Meena N. Jadhav, Associate Professor, CTS No 4842/A-6 Flat No S-04, Sadashiv Residency, Near Shivalaya Temple, $11^{\text {th }}$ Cross, Sadadhiv Nagar, Belagavi, Karnataka, India Emailshubhamj2003@yahoo.co.in

\begin{abstract}
Dermatofibrosarcoma protuberans (DFSP) is an uncommon cutaneous spindle cell tumor of mesenchymal origin with intermediate malignant potential. It usually arises in the dermis and subcutis of the trunk and proximal extremities. It has high tendency for local recurrence but low rate of distant metastasis. We present a case of 26 year old male presented as a recurrent mass in the chest wall diagnosed as spindle cell tumor suggestive of DFSP on cytology and confirmed by histopathology and immunohistochemistry.
\end{abstract}

Key words: Cytology, Dermatofibrosarcoma Protuberans, Recurrent

\section{Introduction}

Dermatofibrosarcoma protuberans (DFSP) is a rare soft tissue tumor of intermediate malignancy commonly seen in the trunk and proximal extremities [1]. The tumor usually arises in the dermis and subcutis [2]. It accounts for $0.1 \%$ of all cutaneous neoplasms [3]. It tends to recur in up to $50 \%$ of the cases but rarely metastasizes [4]. Fine needle aspiration cytology (FNAC) is being used as a diagnostic modality for initial diagnosis as well as recurrences and metastases of soft tissue lesions [5]. It is a safe, reliable, cost effective tool with an overall diagnostic accuracy of $90 \%$ in soft tissue tumors [6]. DFSP has characteristic clinical, cytologic and histologic features. FNAC appears to be very useful in the diagnosis of recurrent and metastatic DFSP [7].

Studies on FNAC of DFSP are very rare [1]. There are only 33 cases reported in the English literature [3]. We present the FNAC features of recurrent DFSP of the chest wall which recurred one year after local excision.

\section{Case Report}

A 26 year old male patient was admitted to the hospital with history of recurrent swelling over the left anterior chest wall of seven months duration.

The patient was operated for similar swelling at the same site one year back and was diagnosed as dermatofibroma in another hospital. On examination, a multinodular, mobile, nontender, firm mass was seen over the left anterior chest wall measuring $10 \times 8 \mathrm{~cm}$.

The skin was stretched and shiny with a linear healed scar over it (Fig 1a). Computed tomography (CT) of the thorax showed an illdefined heterogenously enhancing lobulated soft tissue density mass measuring $7.2 \times 5 \times 4.7 \mathrm{~cm}$ in the subcutaneous tissue in the left anterior chest wall (Fig 1b).

Manuscript received: $16^{\text {th }}$ March 2017

Reviewed: $26^{\text {th }}$ March 2017

Author Corrected: $3^{\text {rd }}$ April 2017

Accepted for Publication: 10 $0^{\text {th }}$ April 2017 


\section{Case Report}

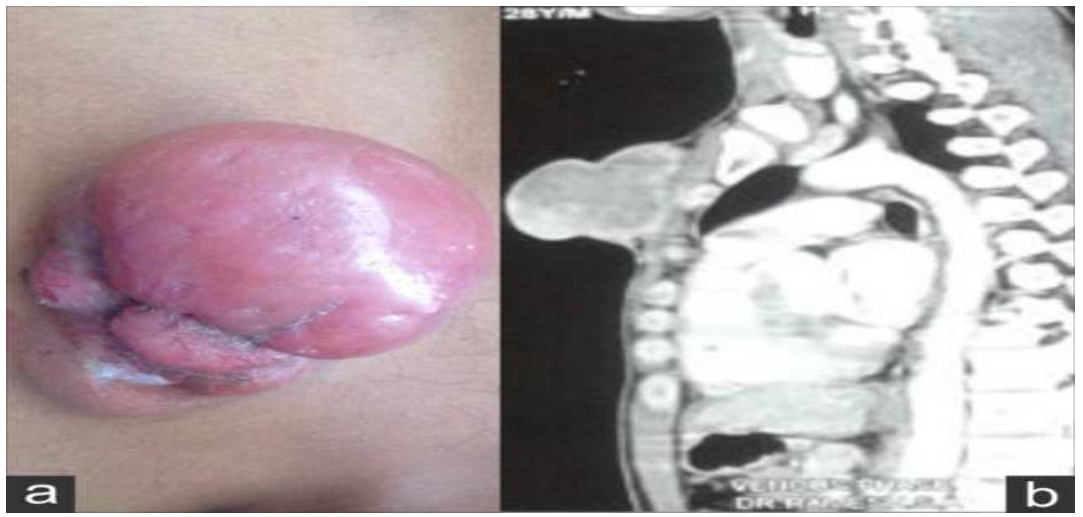

Fig-1 a): Gross appearance of multinodular mass over left chest wall b) CT scan showing heterogenously enhancing soft tissue mass over chest wall.

FNAC was done with 23-guage needle and 10cc syringe. Aspirate was hemorrhagic and smears were prepared. Wet fixed smears were stained with Papanicolaou stain, Hematoxylin and Eosin (H\&E) stain. Air dried smears were stained with May-Grunwald-Giemsa (MGG) stain. Additional material was used for cell block preparation. Cytology smears showed cellular aspirate composed of monotonous population of bland spindle cells arranged in cohesive clusters with storiform pattern and scattered singly. These cells had scanty cytoplasm with fine chromatin and inconspicuous nucleoli. There was no mitosis or necrosis (Fig 2). Fragments of collagenous metachromatic matrix were seen in MGG smears (Fig 3). There were no giant cells or inflammatory cells or adipocytes or melanin pigment.

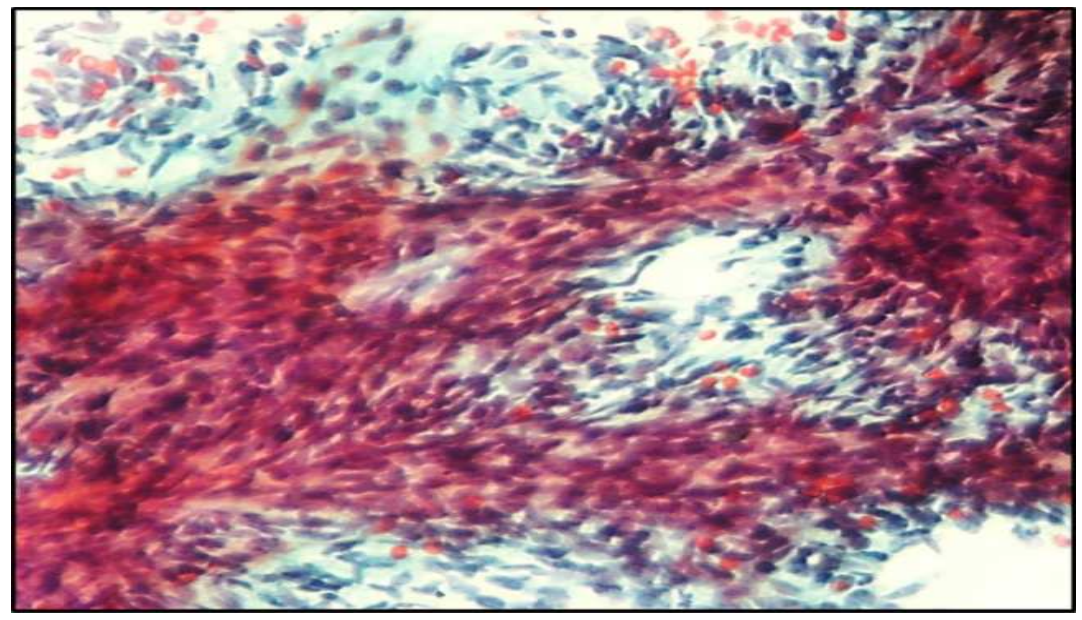

Fig-2: Microphotograph showing spindle cells in storiform pattern and scattered singly (Pap,X 400).

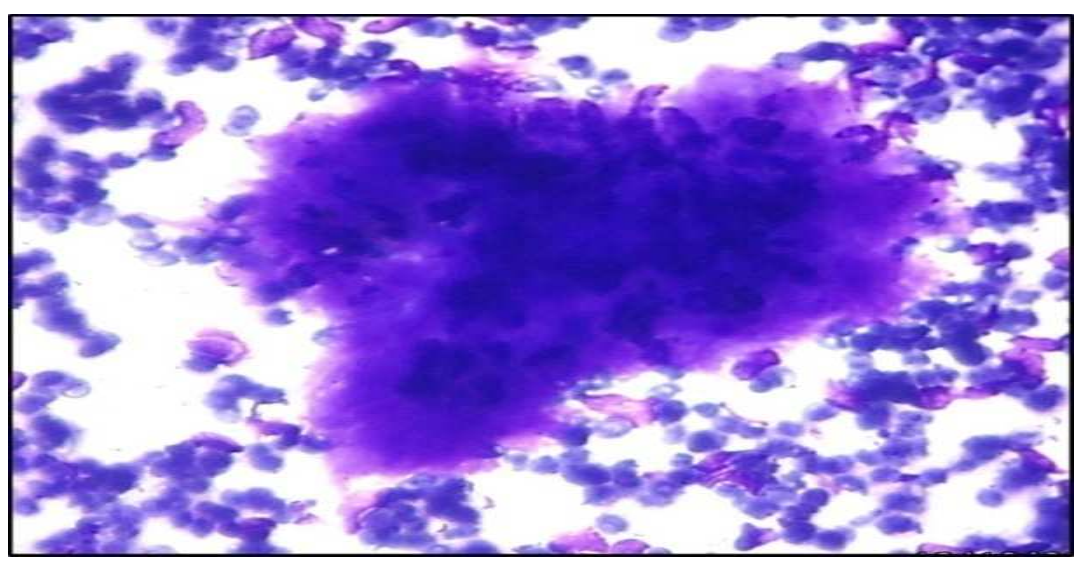

Fig-3: Microphotograph showing tumor cells embedded in collagenousmetachromatic matrix (MGG, X 400) 


\section{Case Report}

Based on these a diagnosis of spindle cell tumor suggestive of recurrent DFSP of anterior chest wall was offered. The cell block preparation showed bland spindle cells in H\&E stain and were inconclusive. Wide excision was done with reconstruction of full thickness skin graft. The excised mass showed tumor in the dermis made up of bland spindle cells in repetitive storiform pattern infiltrating into adjacent adipose tissue. Immunohistochemistry (IHC) showed diffuse CD 34 positivity of tumor cells (Fig 4) and confirmed the diagnosis. The patient is doing well with no evidence of recurrence or metastasis on 15 months of follow up.

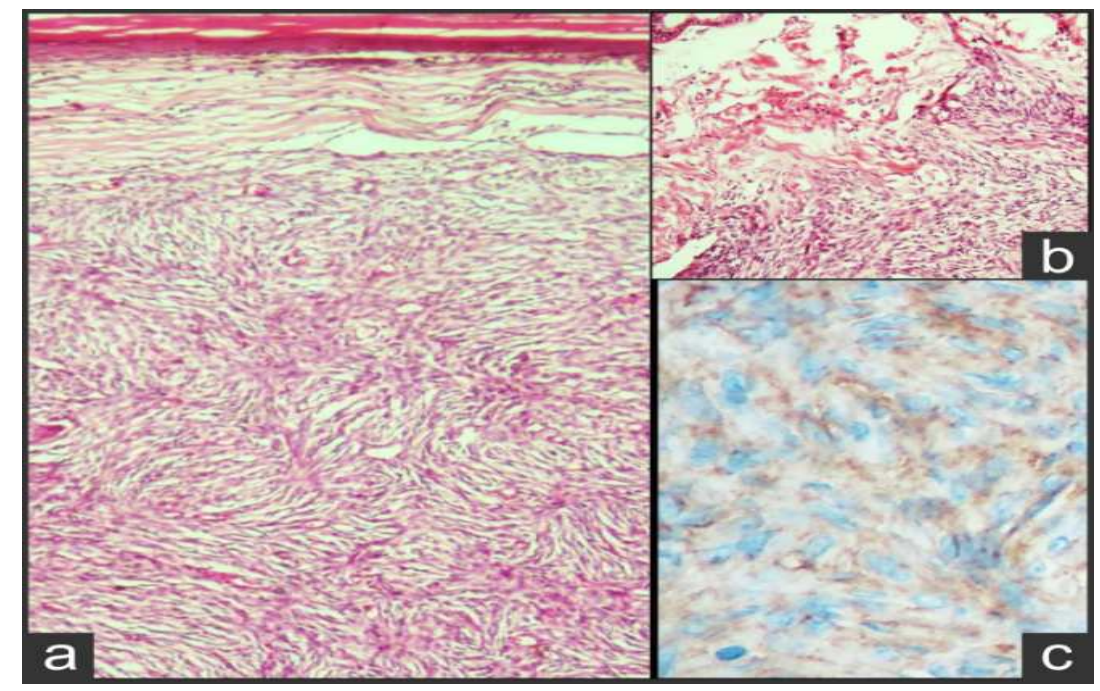

Fig-4: Microphotograph in histology section showing a) storiform pattern of tumor cells

(H\&E, x 200) b) with infiltration into adjacent fat (H\&E x 200) and are c) immunopositive for CD 34 (IHC,x400).

\section{Discussion}

DFSP was first described by Darriers and Ferrand as 'progressive and recurrent dermatofibroma' in 1924. Later it was named as DFSP by Hoffman in 1925 [8]. It is classified with fibrohistiocytic neoplasms. It is more often seen in young adults with male predominance. Though common on the trunk and extremities, hands are spared [8]. On FNAC typically the smears are cellular composed of cohesive clusters of plump spindle cells with storiform pattern embedded in collagenous matrix with singly scattered cells in the background. In recurrent lesions the myxiod stroma is more prominent [8]. DFSP can progress to fibrosarcomatous DFSP which can metastasize [2].

The diagnosis of DFSP on FNAC can be challenging due to morphological overlapping of other spindle cells lesions. Studies have shown that combination of clinicopathological features and ancillary techniques are crucial in establishing a correct diagnosis [2,9]. In the present case the previously excised tumor diagnosed as dermatofibroma was reviewed and the diagnosis was changed to DFSP.

The differential diagnoses considered were dermatofibroma, nodular fascitis, fibromatosis, neural tumor and fibrosarcoma. In the present case the smears showed monomorphic spindle cell population without any inflammatory cells, giant cells and hemosiderin laden macrophages in contrast to dermatofibroma. The possibility of nodular fasciitis was ruled out in view of slowly growing mass, absence of inflammatory cells, pleomorphic cells and ganglion - like cells.

Fibromatosis is a deeply located lesion with sparse cellularity and more collagenous stromal fragments in contrast to DFSP, hence was not consistent with the diagnosis of fibromatosis. IHC is more helpful in problematic cases. DFSP shows consistent positivity for CD 34 and negative for S-100 protein. In the present case IHC studies were not possible either on cytologic smears or cell block preparation but was done on histological sections for confirmation of diagnosis. The histogenesis is controversial and is thought to be of fibroblastic, fibrohistiocytic or histiocytic origin [1]. There is $\mathrm{t}(17 ; 22)$ involving COLIAI (Collagen type 1A 1gene) and $\mathrm{PDGFb}$ gene respectively [3].

The treatment of choice is excision with safe margin of 2-3 cms. [3] DFSP show recurrence in $50 \%$ of the cases [4]. Metastases are reported in $1.5 \%$ of cases. Recurrent DFSP often behaves in a more aggressive fashion with metastasis in few cases [10]. 


\section{Conclusion}

DFSP should be considered in a recurrent spindle cell tumor seen on FNAC especially presenting as multinodular, protuberant mass hence avoiding the patient undergoing mutilating surgery.

Funding: Nil, Conflict of interest: None initiated, Permission from IRB: Yes

\section{References}

1. Rekhi B, Saxena S, Burra U. Fine Needle Aspiration Cytology of Dermatofibrosarcoma protuberans. J Cytol 2004; 21(3):156-58.

2. Domanski HA, Gustafson P. Cytologic features of primary, recurrent, and metastatic dermatofibrosarcoma protuberans. Cancer. 2002 Dec 25;96(6):351-61.

3. Nikumbh DB, Gondane SR, Kanthikar SN, Dravid NV, Ahirrao BM. FNA Diagnosis of Primary Dermatofibrosarcoma Protuberans Fibrosarcoma Variant - A Rare Entity. Indian Journal of Pathology: Research and Practice 2016;5(2) DOI : http://dx.doi. org/ 10. 21088/ijprp.2278.148X.5216.24

4. Goldblum JR. CD34 positivity in fibrosarcomas which arise in dermatofibrosarcoma protuberans. Arch Pathol Lab Med. 1995 Mar;119(3):238-41.
5. Khalbuss WE, Teot LA, Monaco SE. Diagnostic accuracy and limitations of fine-needle aspiration cytology of bone and soft tissue lesions: a review of 1114 cases with cytological-histological correlation. Cancer Cytopathol. 2010 Feb 25;118(1):24-32. doi: 10. 1002/cncy.20058.

6. Chandrashekhar R, Sharma R, Gahine R, Bhawnani $D$. Evaluation of fine needle aspiration cytology in the diagnosis of soft tissue tumors and its correlation with histopathological findings. Int J Res Med Sci 2015; 3 (3): 723-29.

7. Zee SY, Wang Q, Jones CM, Abadi MA. Fine Needle Aspiration Cytology of Dermatofibrosarcoma Protuberans Presenting as Breast Mass. Acta Cytol 2002; 46:741-43.

8. McPeak CJ, Cruz T, Nicastri AD. Dermatofibrosarcoma protuberans: an analysis of 86 cases--five with metastasis. Ann Surg. 1967 Nov;166(5):803-16.

9. Domanski HA. FNA diagnosis of dermatofibrosarcoma protuberans. Diagn Cytopathol. 2005 May; 32(5):299-302.

10. Filipowicz EA, Ventura KC, Pou AM, Logrono R. FNAC in the diagnosis of recurrent dermatofibrosarcoma protuberans of the forehead. A case report. Acta Cytol. 1999 Nov-Dec;43(6):1177-80.

\section{How to cite this article?}

Jadhav M.N, Kempula G, Haravi R.M, Kittur S.K. Fine needle aspiration cytology of recurrent dermatofibrosarcoma protuberans presenting as a chest wall mass. Trop J Path Micro 2017;3(2):124-127.doi: 10.17511/jopm.2017.i2.08. 